\title{
The influence of pharmaceutical companies
}

\author{
Paolo Migone \\ Coeditor, Psicoterapia e Scienze umane
}

The Conference Psychotherapies for Anxiety and Depression: Benefits and Costs, organized by Professor Ezio Sanavio in Padua, Italy, on November 6-7, 2016, has been of paramount importance. It was the expression of a deeply felt need in the Italian psychotherapy community. As documented at the Conference, as well as in the resolution of the Scientific Committee, the situation of the treatment for anxiety and depressive disorders is somehow paradoxical: the empirical evidence on the efficacy of psychotherapy for common mental disorders such as anxiety and depression is well documented in the literature (American Psychological Association, 2013), and this efficacy is often superior to medication. For example, Shedler (2010, p. 102) in his meta-analysis found that the Effect Sizes of general psychotherapy for various mental disorders range from 0.73 to 0.85, while the Effect Sizes of antidepressant medications is much lower, within a range of 0.17-0.31 [in a review on cognitive-behavioral therapy (CBT) for depression (Churchill et al., 2001)], the Effect Size was even higher, 1.0, and also psycho-dynamic therapy (PDT) fared well, with Effect Sizes ranging from 0.69 to 1.46). Nevertheless, medication is the most common treatment for these disor-

Correspondence: Paolo Migone, Via Palestro 14, 43123 Parma, Italy.

Tel. +39.0521 .960595 .

E-mail:migone@unipr.it

Key words: Influence of pharmaceutical companies; Effects of psychotherapy; Mood disorders; Anxiety disorders; Epidemic of mental illness.

Citation: Migone, P. (2017). The influence of pharmaceutical companies. Research in Psychotherapy: Psychopathology, Process and Outcome, 20(2), 136-138. doi: 10.4081/ripppo.2017.276

Received for publication: 10 May 2017.

Accepted for publication: 16 May 2017.

This work is licensed under a Creative Commons Attribution NonCommercial 4.0 License (CC BY-NC 4.0).

CCopyright P. Migone, 2017

Licensee PAGEPress, Italy

Research in Psychotherapy:

Psychopathology, Process and Outcome 2017; 20:136-138

doi:10.4081/ripppo.2017.276 ders; psychiatrists, in general, prescribe only drugs and disregard the possibility of suggesting psychotherapy to patients suffering from anxiety or depression. Since evidence-based research is ignored, this can be considered a form of malpractice, and it would be unacceptable in the treatment of medical conditions.

This paradox deserves serious consideration, and the Padua Conference aimed just at discussing in depth this alarming situation that may have harmful consequences on the population suffering from psychological disorders. It deserves attention by the media, insurance companies, mental health services and governmental agencies.

I this brief intervention I would like to mention some of the reasons that could explain why this paradoxical situation persists.

First of all, the entire medical discipline is heavily influenced by pharmaceutical companies. Marcia Angell (2011), who served as editor of what is probably the most important medical journal in the world, The New England Journal of Medicine, wrote a lucid - and disquieting analysis of the current state of psychiatry, highlighting its weaknesses and the heavy influences of drug companies. Big Pharma virtually supports - directly or indirectly every journal and scientific meeting of the field. Without the income due to advertisements, most psychiatric journals would cease publications and many meetings would be canceled (cancellations of important national meetings, due to lack of financial support by pharmaceutical companies, indeed occurred). Also the scientific information that reaches every practitioner is heavily controlled by pharmaceutical companies, and it is well documented that psychotropic medication, such as anti-anxiety and antidepressant drugs, are prescribed mostly by general practitioners; in some countries, medications are freely advertised on the TV and in popular magazines (they too need advertisements for their survival), creating false expectations in the population, wrong beliefs on the etiology and treatment of common psychological problems, and a growing need to seek the advertised drugs from their physicians. Pharmaceutical companies finance most - if not all - Randomized Controlled Trials (RCT) on the efficacy of medications, and this has obvious consequences on the decision of which studies have to be done (those on the drugs that pharmaceutical companies will launch on the market), and especially on the criteria for publication of studies. Publi- 
cation biases related to pharmaceutical companies' interest have been well documented: attempts at limiting the possibility that published RCTs are only those showing the results expected by pharmaceutical companies have been made only few years ago (Migone, 2005, pp. 317-318), so that for many years the empirical evidence on the effects of many drugs has been heavily distorted (only about ten years ago some major medical journals - but not all agreed not to publish those papers whose designs have not been registered in an international databank before their beginning, not after their completion, i.e., depending on the results obtained). However, to think that distorting effects due to the influence of pharmaceutical companies have disappeared would be an illusion. The impression is that often we are not dealing with an Evidence-Based Medicine, but with an Evidence-Biased Medicine.

Many authors have documented the real effects of some classes of psychiatric medications, coming to conclusions that are different from the official truth of pharmaceutical companies and of important sectors of academic psychiatry. Among others, Kirsch (2009), has shown that the effect of antidepressants is not too different from placebo (Fava, 2002), and Whitaker (2010) has reported impressive data on the real effects of antidepressant and antipsychotic drugs. A recent example of how pharmaceutical companies interfere with scientific research is represented by the wellknown case of Study 329 (Migone, 2015) related to the antidepressant paroxetine, that was tested in an important study that brought to its approval by Food and Drug Administration (FDA). However, later it came out that this study had been falsified: it had not been written by its 22 authors but by a ghostwriter of GlaxoSmith Kline (GSK), that selling this drug was able to earn 240 million dollars already in 2001, and only in 2002 it was prescribed to more than 2 millions of children and adolescents.

Another contribution that needs to be mentioned is the intervention by twenty-nine psychiatrists (Bracken et al., 2012) at a debate in the British Journal of Psychiatry on the crisis of psychiatry. In that discussion, while some authors argued that a way to solve the crisis of contemporary psychiatry should consist in an increase of the technological aspects (medication, laboratory tests, etc.), Bracken et al., instead, argued that a psychiatric practice that relies mostly on technological aspects is less effective than a practice that relies more on non-technological interventions, such as a careful listening of the patient's problems, an increased length of the session, attention to the patient-therapist relationship, understanding the meaning of symptoms in the patient's life, etc. To this purpose, they invoked a change of the current paradigm of psychiatry. What is interesting of this contribution is that the authors backed up their position with data from rigorous evidence-based research, not with ideological or theoretically-biased convictions.

If psychiatry can attract investments because of the possible income derived by the commercialization of drugs, of course there is no interest in investing in psychotherapy re- search where there are no drugs to sell (also, any evidence on the efficacy of psychotherapy could interfere with pharmaceutical companies' interest). Since our economic system is based on free market, there is a strong interest in products that can be sold to consumers, not in the well being of consumers themselves. The wellbeing of people does not produce a profit to private companies (on the contrary, illnesses could be profitable because they increase the use of medications). For this reason, psychotherapy research can be supported mainly by public agencies, which makes this area of research, in terms of investments, a sort of Cinderella of all medicine. To this regard, we should be surprised by the fact that the psychotherapy research movement made important advances despite these difficulties. Furthermore, there are problems also in the allocation of resources for research on mental health, because public agencies prefer to invest in basic research (such as neuroscience), that may be remunerative in the long term, and to invest little in clinical research, that is badly needed and would give results in the short term. To this regards, twenty American psychiatrists who have been members of the $\mathrm{Na}$ tional Advisory Mental Health Council of the National Institute of Mental Health (NIMH) of the United States (Lewis-Fernández et al., 2016) have strongly criticized the investment policy of NIMH, which is by far the largest funding institution in mental health in the world.

Economical factors, of course, are not the only reasons why the efficacy of psychotherapy is largely ignored and medication is preferred. After all, the political and economical system of a country are freely chosen by its citizens; there are countries in which medical care is privatized, and countries (such as Italy, France, England, etc.) where there is a National Health Service and the interests of pharmaceutical companies are kept more under control. Important globalized cultural factors are also at play. There is a widespread ideology that is influenced - and influenced by our economical system and that permeates our way of thinking. Due to a widespread lack of knowledge on psychological problems, and to the influence of advertisements in the media, people tend to think that mental disorders can easily go away with a pill like some physical illnesses. The idea that our psychological states derive simply from a biological illness may at times be reassuring, but impoverishes the meaning of our life and makes us difficult to understand why, for example, we feel depressed or well, with consequences at many levels and iatrogenic effects that may induce further illnesses. In the same time, we see an impressive growth of so-called alternative medicine, which has its own market and pharmaceutical companies that advertise their products (the term alternative medicine of course does not make sense because there is only one type of medicine, the one that is effective). The fact that the more we see scientific progress, the more people believes in pseudo-science is a paradox, which can be understood as a reaction by a growing part of the population for the dissatisfaction towards our medicine. 
A recent paper published in World Psychiatry, the official journal of the World Psychiatric Association, depicts very well a critical aspect of the current state of psychiatry (Jorm et al., 2017). Since it has been demonstrated that many people with mental disorders do not receive treatment, the aim of this study was to investigate if diminishing this treatment gap could reduce the prevalence of mental disorders. Data from 1990 to 2015 in four industrialized countries (Australia, Canada, England and the United States) were analyzed, and the results showed that in these 25 years the prevalence of mood and anxiety disorders has not decreased at all - actually, in some cases it increased despite a substantial increase in the provision of treatment, particularly antidepressants. Several hypotheses for this lack of improvement were examined and, interestingly, no evidence was found that this lack of improvement was due to an increase of risk factors or of reporting of symptoms because of greater public awareness of common mental disorders. A strongly supported hypothesis for the lack of improvement was that much of the treatment provided does not meet the minimal standards of clinical practice guidelines, i.e., the problem is that this augmented psychiatry is not good psychiatry (Migone, 2009). Quantity must not be confused with quality. Whitaker (2010) and Angell (2011) make the same point, and talk of an epidemic of mental illness that increases more and more with the progress of psychiatry (see also Moynihan \& Cassels, 2005).

Given this picture, it seems that there is no reason to be optimistic. However, the Improving Access to Psychological Therapy (IAPT) initiative, presented by David Clark (2016) at the Padua Conference, is a real novelty in our field. The English government has been able to acknowledge - despite the drug culture and propaganda of pharmaceutical companies - the actual evidence on the efficacy of psychotherapy for common mental disorders. Most importantly, IAPT aims not only at alleviating the suffering of many people, but it should also pay for itself, i.e., it would bring economical saving to the National Health Service. Interestingly enough, financial support to IAPT - which is the only instance of a government providing free talking therapy on a mass scale - continued, actually it was even increased, after a new Prime Minister, with a different political orientation, took over.

Time is due for a project similar to IAPT - where training and supervision to mental health professionals play a key role - to develop also in Italy.

\section{References}

American Psychological Association (2013). Recognition of psychotherapy effectiveness. Psychotherapy, 50, 102-109. doi: 10.1037/a0030276; Italian translation [Riconoscimento dell'efficacia della psicoterapia]. Psicoterapia e Scienze Umane, 2013, 47, 407-422. doi: 10.3280/PU2013-003001.

Angell, M. (2011). The epidemic of mental illness: Why? (Part I); The illusions of psychiatry (Part II). The New York Review of Books, 58(11) 20-22 (Part I), (12), 20-22 (Part II); Italian translation [L'epidemia di malattie mentali e le illusioni della psichiatria]. Psicoterapia e Scienze Umane, 2012, 46(2), 263282. doi: 10.3280/PU2012-002008.

Bracken, P., Thomas, P., Timimi, S., Asen, E., Behr, G., Beuster, C., ..., Yeomans, D. (2012). Psychiatry beyond the current paradigm. British Journal of Psychiatry, 201(6), 430-434. doi: 10.1192/bjp.bp.112.109447; Italian translation [Una psichiatria al di là dell'attuale paradigma]. Psicoterapia e Scienze Umane, 2013, 47(1), 9-22. doi: 10.3280/PU2013-001002.

Churchill, R., Hunot, V., Corney, R., Knapp, M., McGuire, H., Tylee A., \& Wessely, S. (2001). A systematic review of controlled trials of the effectiveness and cost-effectiveness of brief psychological treatments for depression. Health Technology Assessment, 5(35), 1-173. doi: 10.3310/hta5350.

Clark, D. (2016). L'esperienza inglese: Improving Access to Psychological Therapies. Valutazione dei risultati. Presented at the Conference "Psychotherapies for Anxiety and Depression: Benefits and Costs", Padua, Italy, November 6-7, 2016.

Fava, G.A. (2002). Long-term treatment with antidepressant drugs: the spectacular achievements of propaganda. Psychotherapy and Psychosomatics, 71(3), 127-132. doi: 10. 1159/000056279.

Jorm, A.F., Patten, S.B., Brugha, T.S., \& Mojtabai, R. (2017). Has increased provision of treatment reduced the prevalence of common mental disorders? Review of the evidence from four countries. World Psychiatry, 16(1), 90-99. doi: 10.1002/ wps. 20388 .

Kirsch, I. (2009). The emperor's new drugs: exploding the antidepressant myth. London: The Bodley Head; New York: Basic Books. Italian translation [I farmaci antidepressivi: il crollo di un mito]. Milan: Tecniche Nuove.

Lewis-Fernández, R., Rotheram-Borus, M.J., Betts, V.T. (2016). Rethinking funding priorities in mental health research. British Journal of Psychiatry, 208(6), 507-509. doi: 10.1192/bjp.bp.115.179895. Italian translation [Ripensare le priorità nei finanziamenti della ricerca sulla salute mentale]. Psicoterapia e Scienze Umane, 2017, 51(1), 119-124. doi: 10.3280/PU2017-001007.

Migone, P. (2005). Farmaci antidepressivi nella pratica psichiatrica: efficacia reale. Psicoterapia e Scienze Umane, 39(3), 312-322

Migone, P. (2009). La "cattiva psichiatria”. Il Ruolo Terapeutico, $110,65-72$.

Migone, P. (2015). Problemi della ricerca farmacologica: il caso dello "Studio 329". Psicoterapia e Scienze Umane, 49(4), 589-594. doi: 10.3280/PU2015-004003.

Moynihan, R., \& Cassels, A. (2005). Selling sickness. How drug companies are turning us all into patients. Crows Nest (Sydney): Allen \& Unwin. Italian translation [Farmaci che ammalano, e case farmaceutiche che ci trasformano in pazienti]. Modena: Nuovi Mondi.

Shedler, J. (2010). The efficacy of psychodynamic therapy. American Psychologist, 65, 2: 98-109. doi: 10.1037/a0018378. Italian translation [L'efficacia della terapia psicodinamica]. Psicoterapia e Scienze Umane, 2010, 44(1), 9-34. doi: 10.3280/PU2010-001002.

Whitaker, R. (2010). Anatomy of an epidemic: magic bullets, psychiatric drugs, and the astonishing rise of mental illness in America. New York: Crown. Italian translation [Indagine su un'epidemia. Lo straordinario aumento delle disabilità psichiatriche nell'epoca del boom degli psicofarmaci]. Rome: Fioriti, 2013. See the video: www.youtube.com/watch?v= dNXQExuCZeM\&feature=youtu.be 